\title{
Unemployment and Education Problems in Egypt
}

\author{
[Dr Mohamed El Khouli]
}

\begin{abstract}
This study aims to investigate the relationship between some educational variables and unemployment in Egypt and determine the most important educational variables influencing the high rates of unemployment during the period (2002-2012). Thus it can determine the priorities of the Egyptian government when dealing seriously in order to solve the unemployment problem appropriately, with regard to the reduction of unemployment rates in the near future. More importantly, the results has shown that the No. of graduates of theoretical facilities has a significant impact on increasing the No. of unemployed in Egypt, according to the target period by the current study.
\end{abstract}

Keywords-Education, Unemployment, Higher Education Systems (HES), Egypt.

\section{Introduction}

Theoretical and empirical explanations of the relationship between the unemployment and educational systems have been studied widely by researches in many countries, as well as further comparative studies to unemployment differentials based on educational attainment, which was different from one country to another according to the circumstances of each state. However, among these studies, only a few incorporate the effect of educational status into the set of explanatory variables on the unemployment issue based on the in-depth statistical perspective, in particular in Egypt.

The present study considers as a try for contributing to address this research gap by analyzing the role of the most important educational variables on unemployment. In particular, unemployment among Arab youth reached $25 \%$. And this according to a the results of survey of 3 thousand people representatives for 6 Arab countries was conducted by Booz Company consulting and declared in Abu Dhabi summit media in 2013, and that many of them do not trust the quality of education available and its ability to solve the problem of unemployment(1). Several previous studies report associations between education and the incidence and duration of unemployment. And some of them pointed that each year of schooling up to 12 years reduces the expected duration of unemployment by over $4 \%$, and that the acquisition of qualifications required at ordinary levels or above reduces the expected unemployment duration by $12 \%$ (2).

Concerning to educational status in Egypt, educational attainment rising (1998 - 2002), i.e., Primary enrollment rate $73 \%-96 \%$ for Egypt and Secondary Enrollment rate $50 \%$ to $85 \%$. Substantial progress on gender disparities at both primary and preparatory levels, and there was enrolling even greater numbers in primary school. Moreover, the total population in Egypt amounted for 57,434,884 inhabitant according to last formal census in 2006 issued by (CAPMAS), and the percentage of illiterates was $30 \%$ nearly of the total, while whose have university education or over constitutes only $9.6 \%$ of the total, and the remaining their education ranges between intermediate or under-intermediate or knowing just read and write. Consequently, the percentage of illiterates was the highest compared to other educational classifications where illiteracy rate among females was $37 \%$, while $22 \%$ among males. On the contrary, the percentage of males have tertiary education or higher is $11 \%$, while females amounted to $7.8 \%$. As a result of the above, the current study focused on the link between educational status and unemployment, especially the World Bank in 2008 pointed that there was need to reform education system to meet the increasingly competitive market and realize the potential of large in light of growing youth population. And males' unemployment in Egypt was highest among technical secondary graduates in Urban during 1998-2006, whereas females' unemployment was highest among university graduates, who are the only group to have experienced an increase in unemployment during the same period. So, this paper is directed to an audience of global policymakers and serves as the technical background paper for those interested and involved in studying the link between educational variables and unemployment issues, and addresses any aspects of the defect or imbalance with respect to those issues in Egypt as one of the developing countries that need international cooperation and efforts of all relevant international organizations holders concerning to these issues.

\section{Statement of the Problem}

Developing the education is considered key importance in addressing the unemployment problem and the development for the plans and strategies target to this matter, but this link is often ignored, in particular in Egypt. As indicated by the World Bank in 2009 that the education levels of the burgeoning labor force in Arab Mediterranean Countries, including Egypt, were not suited to meet the growing labor demand, especially for workers with medium-level skills. Furthermore, ESCWA in 2005 has pointed out that the rise in unemployment among Arab youth reflects the existence of problems associated with the management of educational outcomes that do not fit in with the actual needs of the labor market. As, the ministry of manpower in Egypt in 2010 declared that the education and training system was unable to give young people the skills required for the job market. And this challenge is not just to create jobs for those youth only, but also in how to provide them by the best quality of educational opportunities. Wherefore, this study will try to review major trends of some educational variables available for the period 2002-2012 by using the advanced statistical methods, e.g., No. of graduates and drop-out rates of education...etc.

Sadat Academy For Management Science

Cairo, Egypt 
In this context, it will put particular emphasis on determining the most important of these variables that have the highest influence on increasing the No. of unemployed in Egypt during this target period by this study.

\section{Objective of the study}

The main objective of the study is to kick-start a highlighting and investigates at the same time which educational variables that have an effect on increasing the unemployed in Egypt. In order to address the stated objective, the following hypotheses was tested:

1. There was no relationship between educational factors and unemployment in Egypt.

2. The educational factors did not affect the unemployed in Egypt during 2002-2012.

The conceptual framework shows the proposed educational factors that are associated with unemployment. The study just focused on the educational factors (No. of graduates, No. of students, drop-out rate..) that were viewed as influential in increasing No. of unemployed in Egypt during 2002-2012. And this in turn is one of the main factors affecting negatively on further exacerbate the social and economic problems in Egypt, as a direct result of the unemployment issue that associated by deteriorating the educational systems. This requires quick action towards the reform and development of education systems, especially higher education, and the rational relationship following will reflect this link as follows:

\begin{tabular}{||l|l||}
\hline \multicolumn{1}{|c|}{ Educational Variables } \\
\hline - No. of graduates from theoretical faculties \\
- No. of graduates from practical faculties \\
- No. of graduates from technical education \\
- No. of students enrolled in theoretical faculties \\
- No. of students enrolled in practical faculties \\
- Dropout rate of primary education \\
- Dropout rate of secondary education \\
- The average density in the classroom
\end{tabular}

Figure 1. Conceptual framework illustrating Educational factors associated with the unemployment that were proposed by the current study

\section{Literature Review}

Previous research has shown that education has substantial impacts on labor market outcomes such as earnings and employment as well as non-market outcomes such as health, longevity, civic participation and criminal activity. One of studies analyzed the effects of demographic and education changes on unemployment rates in Europe using a panel of European countries for the 1980-2000 period and its results has shown that adult workers and more educated individuals, in general, experience lower unemployment rates (3). In addition, a strong relationship between unemployment and education has been found in a number of studies, pointing out to the probability of unemployment is unequally distributed among various groups in societies with considerable differences depending on educational status and No. of qualifications (4). One study confirmed that a major benefit of education is the lower risk of unemployment at higher educational levels (2). More studies interested in studying the relationship between the education and unemployment, form example one study analyzed the link educational attainment and unemployment risk in a French-German comparison (5). Another study investigated the relationship between education and long-term unemployment and showed that an individual to be in long-term unemployment decreases with his educational level, and unemployment rates are negatively correlated with educational levels (6). Additional study investigated the causal effects of education on individuals' transitions between employment and unemployment, and showed that education significantly increases re-employment rates of the unemployed (7). But the matter was different for the relationship between education and unemployment in Egypt, for example there was a study pointed out that Egypt is facing a marked "youth bulge" and therefore has a high rate of youth unemployment, particularly among the highly educated, (8). In this study, we try to examine the negative role played by some educational variables on increasing the unemployed in Egypt, although many studies in developed countries have confirmed the positive role of the education in labor market adjustment to change, and additional education improves the ability of the labor force to adjust to economic shocks. In this context, it noted that these previous studies have reflected the extent of the existence of an implicit reference to the role of educational variables in reducing the worsening problem of unemployment towards higher rates. This is considered as motivation for the current study to signal clearly to monitor the core role of the education in Egypt for addressing the unemployment. This issue is witnessing increasing demand through the prospective students to enroll in various grades, in addition to increasing in the number of graduates with higher education, which is constituted a negative impact on the high rates of unemployment unless there is the availability of potential for investment in these human capacities well. And therefore the study will pursue to shed light on the most important educational variables in influencing until be easier by the decision makers to include these variables within the policies and plans addressing of the unemployment at the national level.

\section{v. Methods}

This study will depend on descriptive and explanatory methods simultaneously to achieve its objectives, besides the quantitative approach. This study is a longitudinal study that depends on time series design which measurements of some variables are taken at different points in time, i.e. during the period 2002-2012, in particular the Central Agency for Public Mobilization and Statistics (CAPMAS) (9). And this due to the official data in Egypt for this period is available in a consistent and adequate shape. The total area of the Arab Republic of Egypt reaches nearly $1.010 .000 \mathrm{Km} 2$, while the 
populated area reaches $78990 \mathrm{~km} 2$ representing $7.8 \%$ of the total area (10), which is located in the northeast corner of Africa and southwest corner of Asia. Moreover, appropriate statistical methods will used to realize the aims of the study, such as the percentages and frequencies. In addition to the use of the multi regression analysis to determine the most important variables that has impact on increasing the No. of unemployed in Egypt through the target period. The present study will depend on some charts to reflect the relationships between the unemployment and some educational variables by following the trends of unemployment across this period that be associated with these variables.

\section{Results}

In this context of the current study, the unemployment $\%$ and the general characteristics of some educational variables in Egypt will be reviewed during the period 2002-2012, according to the statistics that issued by the Central Bureau of Statistics and the general mobilization Arab Republic of Egypt, as be shown in table (1). The results in table No.1 have shown the trends of unemployment rates in conjunction with reviewing of the most important of educational indicators proposed that may be have an impact on the unemployment rate in Egypt during the target period. These results also showed the presence of rising remarkably the unemployment rate in Egypt in 2012, compared to the others years, where stood at $12.7 \%$, which is considered the highest unemployment rate that occurred during the target period, and perhaps to many influences, including the one of implications of the Egyptian revolution in January 25, and thus the deterioration of the economic and security situation in Egypt.

The results pointed that there was a large superiority in No. of graduates of theoretical faculties in Egypt compared to their counterparts from the graduates from practical faculties across all the years targeted by the current study, as the No. of theoretical faculties graduates actually amounted to three times the No. of practical faculties graduates. And this fact will be reflected by following figure with respect to the No. of graduates from Egyptian universities, according to their

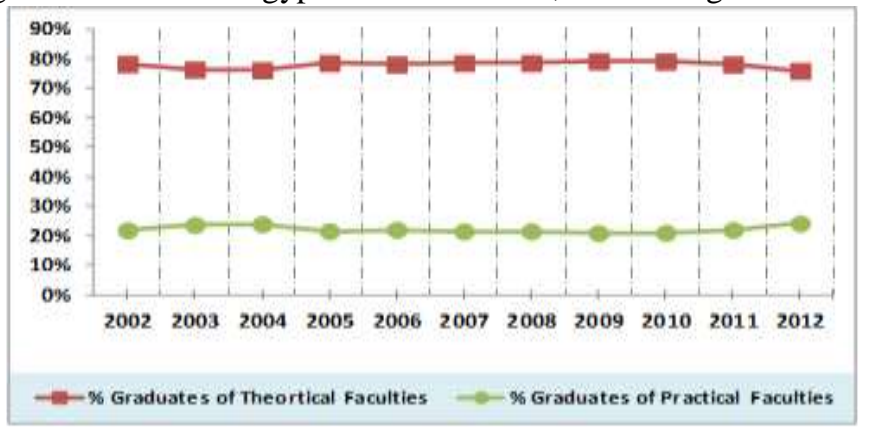

specialties whether theoretical or practical

Figure 2. The \% of graduates from universities in Egypt during (2002-2012)

As well as this case is identical also for the No. of students currently enrolled in theoretical disciplines at the universities Egyptian compared to the No. of students enrolled in practical disciplines, where their total amounted for about three times as well, and this may constitute a clearly one aspect of a defect in the application of education systems efficiently and effectively and trying to link them to the needs of the labor market that are escalating continuously. This result may be considered as a key factor in creating the inability to meet the requirements of the labor market of some practical disciplines and the sufficiency of theoretical disciplines at the same time until reach the saturation degree, thus contributing to the growing problem of unemployment in Egypt during the coming period. Therefore, the need arises to create a balance between the disciplines that fill the needs of the labor market and the No. of graduates required for that matter, besides the necessity of providing them all the knowledge and modern skills that correspond to the international standards in these disciplines to increase the open employment opportunities and reinforce the ability of these graduates for competition at both domestically and internationally level. While the results in table (2) shows the values of the Pearson correlation coefficient(s) between the No. of unemployed in Egypt on the one hand, and between some educational variables that proposed by the study on the other hand. It has shown that the highest significant correlation was between the No. of graduates of theoretical faculties and the No. of unemployed, which reflects a strong relationship direct correlation between the two variables and there was an evidence to the influenced by each other, whereas the hypotheses of the current study suggests the existence of the effect of some educational variables on increasing the No. of unemployed, i.e. like No. of graduates from certain disciplines. Furthermore, there is an inverse association between the increasing the No. of unemployed in Egypt, and decreasing both of the number of graduates and students who have theoretical, the level of public expenditure on education, and the number of graduates of technical schools.

Thus is what summoned this study to try the use of regression analysis technique for determining which of these variables included in the previous correlation matrix that have the most highest impact on increasing No. of the unemployed in Egypt during the target period, as its results be clear by the table No. (3). The findings of the regression analysis using the Stepwise method revealed that the value of R-Square is equal to 0.654 ; which means $65 \%$, i.e. the ability or the proportion of these independent demographic variables to contribute in the interpretation of contrast and predict by the dependent variable ( No. of unemployed). And this indicates that this model is fits to the target purpose for using regression relationship, and the test of variance analysis (ANOVA) has confirmed on the significance of this relationship, where the $\mathrm{F}$ value amounted to 7.462; which is significant at a level less than 0.05 , and thus this indicates a significant of regression relationship, i.e. there is a relation existed between the dependent variable and the independent variable in the model. Accordingly, The data in table (3) showed that increasing the No. of graduates of theoretical faculties affects by standard unit amounted 0.694 on increasing the No. of unemployed in Egypt, according to the target period by the study from 2002 to 2012. And this variable only of the others variables proposed in the model has the greatest influence on dependent variable, which reflects the necessity of the reform or improvement the higher education systems in Egypt to address this problem in Egypt across the coming years for obtaining on positive implication in the future or as soon. 


\section{viI. Conclusion \& Recommendation}

This paper examines the relationship between educational variables and the unemployment, and determining which of these variables has a significant probability to increase the unemployment in Egypt during the period 2002-2012. Considering the full data that available from the CAPMAS during the target period, the results seem to confirm our initial hypothesis that the higher the educational level, there are the highest probability for falling into unemployment issue, especially in light of the failure of the higher education systems to meet the needs of the labor markets of scientific disciplines required, besides, with what emphasized by the results of the current study that rising graduates of theoretical faculties in Egypt contributes to increase No. of unemployed. Notably, that the results indicated that graduates of theoretical faculties constitute the $75 \%$ of the total graduates in Egypt. And this result contrasts with what referred by some modern studies for European States. The conclusions of many previous studies in developed countries concluded that the development of education systems can be key factor to address the unemployment problem, and although education attainment plays a significant role throughout reducing the unemployment rates, there is an increase in these rates among that who have obtained a higher education in Egypt, which confirms the assumption of lacking of graduates to the skills that meet the needs of modern labour market, due to the weakness of education systems and its possibilities, and shortage available resources as well. Moreover, the ability of these systems was lower to emulate modern universities systems and the marketing for its graduates on a global level still weakly. And this result due the monopoly of many western institutions to the culture of quality and accreditation systems without other.

Furthermore, this study urges the targeting the effect of the other educational variables as determinants of long-term unemployment after breaking down the data by level of governorates and other classifications that will be important for decision makers. Also, as an extension of the work presented in this study, we recommend more efforts working for on an expanding in studying the impact of the educational status by comparing the unemployment among many country that have the same conditions, and we aim at exploring further background concerning the link between education reform and addressing unemployment in Egypt and Arabic countries compared to developed countries, and other educational aspects which may affect the motivation to exit unemployment or improving its rates in Egypt especially.

This study encourages to find effective educational policies options by the officials about this field in Egypt that can support the development of more attractive jobs in Egypt's private sector and lead to job creation and inclusive growth. And the findings of this study can contribute to building a foundation for designing youth employment policies in Egypt by higher education systems that based on open rehabilitation centers and professional recruitment fairs. And the need to develop initiatives to attract different sectors and reviewing the jobs that are more distinctive for their graduates. These steps could significantly contribute to an increase in the rates of a private sector employment among fresh-graduates Egyptian job seekers, as well as the possibility to the establishment of good relations between the graduates and the labor markets generally.

\section{References}

[1] Al-Ittihad Newspaper, Issue No. 13987, the Forty-fifth year, Abu Dhabi, 23 October, 2013.

[2] Mincer, J.,'Education and Unemployment', NBER working papers series, No. 3838, National Bureau of Economic Research, Columbia University, New York, USA, 1991

[3] Biagi, F. \& Lucifora, C, 'Demographic and Education Effects on Unemployment in Europe: Economic Factors and Labour Market Institutions', IZA Bonn, No. 1806, Germany, 2005.

[4] Wolbers, M., 'The effects of level of education on mobility between employment and unemployment in the Netherlands', European Sociological Review, 16 (2): 185-200, 2000.

[5] Charlotte L., 'Education and Unemployment: A French-German Comparison, Center for European Economic Research, No. 03-34, from http//www.ftp://ftp.zew.de, Paris, 2013.

[6] Garrouste, C., Kozovska, K. and Perez, E. A., 'Education and LongTerm Unemployment', the workshop (Geographical Localisation, Intersectoral Reallocation of Labour and Unemployment Differentials), JRC 59305, EUR 24450 EN, Joint Research Centre. Luxembourg: European Union, 2010.

[7] Riddell, W., C, 'The Impact of Education on Unemployment Incidence and Re-employment Success: Evidence from the U.S. Labour Market', Institute for the Study of Labor, IZA DP No. 5572, University of British Columbia, Canada, 2011.

[8] Murata, A.,'Designing Youth Employment Policies in Egypt', Global Economy and Development, International Cooperation Agency Research Institute, Tokyo, Japan, 2014.

[9] The Central Agency for Public Mobilization and Statistics (CAPMAS), 'Bulletin of Labour Force (July - Sep).' Cairo, Egyp, 2013.

[10] Egypt State Information (SIS), from http://www.sis.gov.eg.

[11] J Egypt's Information Portal, 'Statistics \& Databases', The Egyptian The Cabinet, Information \& Decision Support Center (IDSC), Retrieved from http://www.eip.gov.eg [19 Jan. 2014], 2014.

[12] World Bank Washington DC, 'Youth unemployment, existing policies and way forward: Evidence from Egypt and Tunisia', 2008.

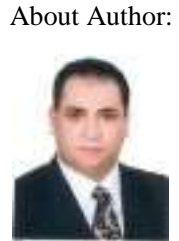

Dr. Mohamed El Khouli Egyptian nationality, was born in Cairo 10/07/1975, and holds a Ph.D. in Biostatistics and Demography from the Cairo University in 200. He is an Associate Professor in Statistics at Sadat Academy for Management Sciences in Cairo. Also he is an expert in different domains like in statistics, demographic analysis, Strategic Planning, Quality Assurance, Corporate Excellence, Measuring Performance, Project \& Risk Management, and Monitoring \& Evaluation. Concerning to his experiences, he worked as the Head of the Planning Section in Western Region Municipality in Abu Dhabi UAE, Quality and Assessment Specialist academic at the University of Qatar, Monitoring \& Evaluation Officer at the Dutch Embassy in Cairo, Auditing of Quality at the Ministry of Higher Education in Egypt, and the manager of Financial Information unit at Ras Al Khaimah -UAE. Dr. Mohammed Al-Khouli, a member and reviwer at Athens Institute for education and Research ATNER, an Affiliate Member at Australian Human Resources Institute AHRI, a member at demographers Egyptians Association in Cairo, a member of the Egyptian Society of Statistics, and a member of the Community Development Association in Fayoum Governorate, and holds a certificates of appreciation from both the Family Development Foundation in Sharjah, and the Center of the Ministry of Culture, Youth and Community Development in the Emirate of Abu Dhabi. 
Proc. of the Fourth International Conference on Advances in Social Science, Management and Human Behaviour - SMHB 2016.

Copyright $\odot$ Institute of Research Engineers and Doctors. All rights reserved.

ISBN: 978-1-63248-116-0 doi: 10.15224/ 978-1-63248-116-0-44

TABLE 1: SOME EDUCATIONAL CHARACTERISTICS IN EGYPT DURING (2002-2012)

\begin{tabular}{|c|c|c|c|c|c|c|c|c|c|c|c|}
\hline Variables & $\mathbf{2 0 0 2}$ & $\mathbf{2 0 0 3}$ & $\mathbf{2 0 0 4}$ & $\mathbf{2 0 0 5}$ & $\mathbf{2 0 0 6}$ & $\mathbf{2 0 0 7}$ & $\mathbf{2 0 0 8}$ & $\mathbf{2 0 0 9}$ & $\mathbf{2 0 1 0}$ & $\mathbf{2 0 1 1}$ & $\mathbf{2 0 1 2}$ \\
\hline Unemployment \% & $10.17 \%$ & $11.01 \%$ & $10.32 \%$ & $11.2 \%$ & $10.6 \%$ & $8.9 \%$ & $8.7 \%$ & $9.4 \%$ & $9 \%$ & $11.99 \%$ & $12.7 \%$ \\
\hline No. of Graduates & 251220 & 260410 & 270762 & 304228 & 311701 & 318727 & 324284 & 332444 & 326298 & 343937 & 334203 \\
\hline • \% Theoretical Faculties & $78.2 \%$ & $76.3 \%$ & $76.1 \%$ & $78.5 \%$ & $78.0 \%$ & $78.5 \%$ & $78.5 \%$ & $79.1 \%$ & $79.0 \%$ & $78.0 \%$ & $75.8 \%$ \\
\hline • \% Practical Faculties & $21.8 \%$ & $23.7 \%$ & $23.9 \%$ & $21.5 \%$ & $22.0 \%$ & $21.5 \%$ & $21.5 \%$ & $20.9 \%$ & $21.0 \%$ & $22.0 \%$ & $24.2 \%$ \\
\hline No. of Uni. Students & 1552622 & 1623685 & 1761376 & 1874752 & 1869848 & 1862734 & 1912132 & 1942518 & 1649986 & 1627339 & 1767699 \\
\hline • \%Theoretical Faculties & $78.2 \%$ & $79.4 \%$ & $80.6 \%$ & $81.7 \%$ & $80.2 \%$ & $79.6 \%$ & $80.1 \%$ & $80.4 \%$ & $79.7 \%$ & $77.7 \%$ & $79.8 \%$ \\
\hline • \%Practical Faculties & $21.8 \%$ & $20.6 \%$ & $19.4 \%$ & $18.3 \%$ & $19.8 \%$ & $20.4 \%$ & $19.9 \%$ & $19.6 \%$ & $20.3 \%$ & $22.3 \%$ & $20.2 \%$ \\
\hline No. of students at Technical educ. & 2149408 & 2214152 & 2199480 & 2090008 & 1981162 & 1793609 & 1361629 & 1252431 & 1260793 & 1607125 & 1628168 \\
\hline • \% males & $53.8 \%$ & $53.9 \%$ & $54.2 \%$ & $54.1 \%$ & $53.1 \%$ & $52.1 \%$ & $53.2 \%$ & $54.0 \%$ & $55.5 \%$ & $54.7 \%$ & $55.6 \%$ \\
\hline • \% females & $46.2 \%$ & $46.1 \%$ & $45.8 \%$ & $45.9 \%$ & $46.9 \%$ & $47.9 \%$ & $46.8 \%$ & $46.0 \%$ & $44.5 \%$ & $45.3 \%$ & $44.4 \%$ \\
\hline Dropout in Primary & $0.87 \%$ & $0.84 \%$ & $0.9 \%$ & $0.49 \%$ & $1.23 \%$ & $1.23 \%$ & $0.7 \%$ & $0.39 \%$ & $0.16 \%$ & $0.39 \%$ & $0.34 \%$ \\
\hline Dropout in preparatory & $3.13 \%$ & $3.02 \%$ & $3.54 \%$ & $3.33 \%$ & $2.9 \%$ & $2.06 \%$ & $6.5 \%$ & $6.42 \%$ & $5.44 \%$ & $5.11 \%$ & $6 \%$ \\
\hline
\end{tabular}

TABLE 2: THE CORRELATION MATRIX BETWEEN NO. OF UNEMPLOYED IN EGYPT, AND SOME EDUCATIONAL VARIABLES PROPOSED IN THE REGRESSION ANALYSIS, (2002-2012)

\begin{tabular}{|c|c|c|c|c|c|c|c|}
\hline Variables & $\begin{array}{c}\text { No. of } \\
\text { Unemployed }\end{array}$ & $\begin{array}{l}\text { No. of } \\
\text { primary } \\
\text { schools }\end{array}$ & $\begin{array}{c}\text { Public } \\
\text { Expenditure } \\
\text { on } \\
\text { Education } \\
\end{array}$ & $\begin{array}{l}\text { Average } \\
\text { density in } \\
\text { classroom }\end{array}$ & $\begin{array}{l}\text { Dropout } \\
\text { rate of } \\
\text { secondary } \\
\text { education }\end{array}$ & $\begin{array}{c}\text { Dropout } \\
\text { rate of } \\
\text { primary } \\
\text { education }\end{array}$ & $\begin{array}{l}\text { No. of stu. enrolled in } \\
\text { practical faculties }\end{array}$ \\
\hline - No. of graduates of practical faculties & -0.511 & $0.737 * *$ & $0.698^{*}$ & 0.445 & 0.570 & 0.422 & 0.590 \\
\hline - No. of graduates of theoretical fac. & $0.726 * *$ & $0.715^{* *}$ & $0.737 * *$ & 0.407 & 0.595 & 0.455 & $0.642 *$ \\
\hline - No. of graduates of technical edu. & -0.260 & $0.798 * *$ & $0.755^{* *}$ & 0.136 & $0.721 * *$ & 0.595 & 0.509 \\
\hline - No. of stu. enrolled in theoretical fac. & 0.163 & 0.302 & 0.157 & $0.636^{*}$ & 0.182 & 0.146 & $0.650^{*}$ \\
\hline - No. of stu. enrolled in practical fac. & -0.105 & 0.507 & 0.529 & $0.730^{* *}$ & 0.306 & 0.246 & 1 \\
\hline - Dropout rate of primary education & 0.518 & $0.604 *$ & 0.329 & 0.205 & $0.758 * *$ & 1 & \\
\hline - Dropout rate of secondary education & 0.422 & $0.704 *$ & $0.624^{*}$ & 0.172 & 1 & & \\
\hline - Average density in classroom & 0.308 & 0.298 & 0.295 & 1 & & & \\
\hline - Public Expenditure on Education & -0.448 & $0.780^{* *}$ & 1 & & & & \\
\hline - No. of primary schools & $-0.620 *$ & 1 & & & & & \\
\hline
\end{tabular}

$(* *)$ Significant at the level less than 0.01

${ }^{*}$ ) Significant at the level less than 0.05

TABLE 3: THE COEFFICIENTS OF REGRESSION MODEL EQUATION USING STEPWISE METHOD FOR EDUCATIONAL VARIABLES AFFECTING THE NO. OF UNEMPLOYED IN EGYPT, (2002-2012)

\begin{tabular}{|c|c|c|c|c|c|}
\hline Variables & $\mathrm{B}$ & Std .Error & Beta & $\mathrm{t}$ & Sig. \\
\hline (Constant) & -364572.5 & 996576.6 & & -0.366 & 0.724 \\
\hline $\begin{array}{c}\text { No. of graduates of } \\
\text { theoretical facilities }\end{array}$ & 40.65 & 14.88 & 0.694 & 2.732 & $0.026^{*}$ \\
\hline
\end{tabular}

Source: Outputs of SPSS Pogrin

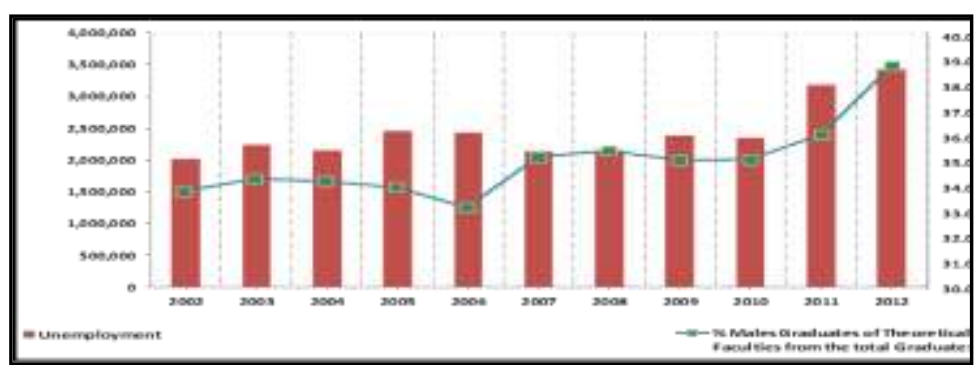

Chart 1: The No. of unemployed in Egypt and its relation with the \% of Males graduates from theoretical faculties from the total graduats 